\title{
PET ANIMALS' BEHAVIOR ANALYSIS: A REVIEW
}

\author{
ARTHI N*, ANNIS FATHIMA A \\ Department of CSE, VIT University, Chennai Campus, Chennai, Tamil Nadu, India. Email: arthiun@gmail.com
} Received: 23 January 2017, Revised and Accepted: 03 March 2017

\begin{abstract}
Nowadays, socializing of humans with pet animals has increased. The pet animals are treated as a part of the family and the physical interaction has also improved owing to the fact that the infected animals are not easily identifiable at an early stage and children are more prone to get infected. This leads to the necessity for monitoring and analyzing the behavior of the pet animals. The current trend is moving toward smart homes as the cameras are getting cheaper and easily available. The vision-based approach is one of the solutions to identify the behavioral changes of the pet animals. In this paper, the study on behavioral analysis of dogs and cats as pet animals is reviewed.
\end{abstract}

Keywords: Behavioral analysis, Pet animals, Dog-human interaction, Cat-human interaction.

(C) 2017 The Authors. Published by Innovare Academic Sciences Pvt Ltd. This is an open access article under the CC BY license (http://creativecommons. org/licenses/by/4. 0/) DOI: http://dx.doi.org/10.22159/ajpcr.2017.v10s1.19630

\section{INTRODUCTION}

A study on domestic animals in the United States shows that the population of dogs and cats is nearly 70-80 million and 74-96 million, respectively. The percentage of households owning dogs is $36.5 \%$ and cats are around $30.4 \%$ in the U.S.; every year, 1.4 million dogs and 1.3 million cats are adopted by pet welfares or pet lovers.

According to the World Health organization, it is estimated that the population of the stray dogs and cats worldwide is around 20 million and 60 million, respectively [1].

From ancient times, the domestic animals are considered as part of their family utilizing them for the household or for their living purposes. In rural India, they are sheltered outside the living place. At present, pet animals such as dogs and cats are becoming a valuable part of sophisticated family and they are accommodated as a family member. The pet population growth in India is around 7 million in 2006 to 10 million in 2011. The pet animal adoption rate is around 0.6 million per year. The pet animals are pampered well; on the other end, the stray animals are abused and starved. To control the population of stray animals, the Animal Welfare Board of India sterilized many stray dogs. It is estimated to be 31,341 in 2014-2015 to avoid swell in population [2].

The emotional feeling of an animal is observed in its behavior. Particularly, domestic animals have a good contact with humans. In ancient days, wolves had a good relationship with humans for hunting and security purposes. As the eras passed by, dogs have taken the place of their counterparts, wolves. Dogs are the first domesticated animal that shares common environment and accompany with humans over 10,000 years. About $40 \%$ of the owners identified dogs as one of their family members and did not see dogs as a stranger. Behavior of a pet can be easily recognized by a human who have good interaction with animal and knowledge about its behavior [3].

Adam used scientific, zoological, and historical approaches to the study of dogs which expands the genetic cognition of the dog's behavior, but also makes use of this knowledge to disclose furtive to behavioral progression in general, even with the ordinary situation of the human beings [4]. Dogs are compared with its predecessors, i.e., wolves, as well as humans to prepare a comparative context that how dogs share their present environmental conditions with others.
Cats have a strong relied communication in its body language. About 4000 years ago, cats were domesticated by Egyptians first to protect their stored foods. Most of the cat's body language is through its ears, head position, tail, and back posture. Compared with other members of carnivore, feline cats are non-aggressive and interactive with people. Depending on their environmental growth, cats learn some vocal communication with their owners and expose their behavior [5]. Cats may flutter their tail from side to side indicating that they like to play or interact with an object or a human. Ear or head movement entitles a better indication of sound observation in any direction.

In animal behavior, environmental science, automated observing and training systems are very useful to monitor the behavior of the pet animals. Computer-aided training/observing systems are used for continuous supervision of animals for recording the data and elimination of potential built-in signs by humans through training and testing. First, the system was tested with a domestic cat of 10 months' age for training. The cat was successfully trained to differentiate three dissimilar spoken words [6].

The vision-based technique allows human to perceive the surroundings and makes easy to analyze the behavior. This study describes complete knowledge about the human-animal interaction, behavioral ecology, and physiological and cognitive evolution of dogs easily. Alain stressed realistic applications for evaluating and encouraging positive feelings that may assist in affording animals with an enhanced value of life [7].

\section{PET ANIMALS' BEHAVIOR ANALYSIS}

The pet animals' behavior is analyzed based on their shelter life, how the infants get infected during interaction with their pets, also how pets help their owners when they are visually blind, and pet-human interaction.

\section{Pets' behavior in shelter}

Animals feel comfortable to live in free environmental atmosphere. Some people have the pet animals in their home. They provide a

Table 1: Pets' behavior in shelter

\begin{tabular}{lll}
\hline Author & Year & Behavioral analysis \\
\hline Morgan and Trombort & 2007 & Artificial cage environment \\
Herron et al. & 2014 & Cage behavior training \\
Patronek et al. & 1996 & Difficulties in shelter \\
Kelly et al. & 2011 & \\
\hline
\end{tabular}


closed artificial cage for their pets. Due to the small space provided by the owners, the pet animals are distressed. Table 1 summarizes the behavior of a pet in a shelter.

Even though the cage contains all the facilities such as food, safety, and health care, animals get stressed due to environmental sources such as artificial lighting, sound, and temperature. Morgan and Trombort reviewed the stress of animals in the artificial atmosphere and changes in their behavioral level. Fig. 1 shows a dog getting stressed arresting in an artificial cage [8].

A dog may feel comfortable in the shelter only after training. Some dogs are adopted from municipal shelter and assigned training from experimental or control group. Experts train the dogs twice a day about cage behavior; it includes positive reinforcement kind behavior with food-filled provision. A blind observer will monitor the dog's behavior in cage on day 0 and day 3 using scan-sampling technique by comparing adoption data with behavioral observation data. After group training, the result reveals that the dog shows a desirable behavior in the cage [9]. Caretakers of animals evaluated and found that most of the animals get behavioral change and psychological effects due to cage environment.

Domestic cats are safe in a home setting environment with their owner's protection. Many cats failed to have a way of life because they are arrested in a shelter. Before adoption, cats spend more time in a shelter with a group of other cats. Kelly Gouveia selected 46 cats in a local shelter and an observer recorded each cat's behavior for 5 minutes each day at three different occasions [10]. Cat's grooming, inactivity behavior, eating time, friendly interaction, and unpleasant struggle with other gender cats are observed and analyzed by the observer. In shelter life, cats are getting more negative encounters and also their stress levels are increased.

Hence, this study emphasizes that adoption of cats is very important to improve the quality of a cat's life and rescue it from a shelter. Some owners will adopt cats without having any knowledge about the cat's behavior. To provide the well-being for cats in an animal shelter, education programs are needed for the pet trainers and the owners [11]. Fig. 2 shows a cat getting stressed when arrested in an artificial cage.

\section{Pets' interaction with infants}

An adult can easily analyze the dog's behavior and prevent them from dogs' bite. In general, children like to play with pet animals without any knowledge about the dog's behavior; mostly preschoolchildren get infected by dog's bite. Table 2 summarizes the infant-pet relationship to avoid infections.

Wilson et al. proposed a study on preschoolchildren and described how they can learn dog's behavior and prevent from dog's bites. Children in the age group from 3 to 5 years are enrolled and the dog's reaction was verified before and after an educational intervention or wild animal control group. Children were able to judge the relevant behavior after the training intervention [12-14].

Children have more interaction with dogs and cats more than humans. Health problems such as asthma affect the children those who are living with dogs, especially newborn babies, school-aged children and preschoolchildren. To determine the risk of asthma, researchers conducted a study to control the asthma problem and they evaluated newborn children in Sweden from 2001 to 2012 [15]. During that study period, 1,011,051 children were born. This analysis showed a report on reducing asthma risk in both school-aged and pre-schoolchildren due to their less contact with dogs than children younger than 3 years. This information may be helpful in making assessment on families and physicians on the correctness and instance of early animal revelation. Fig. 3 shows the interaction between a dog and an infant.

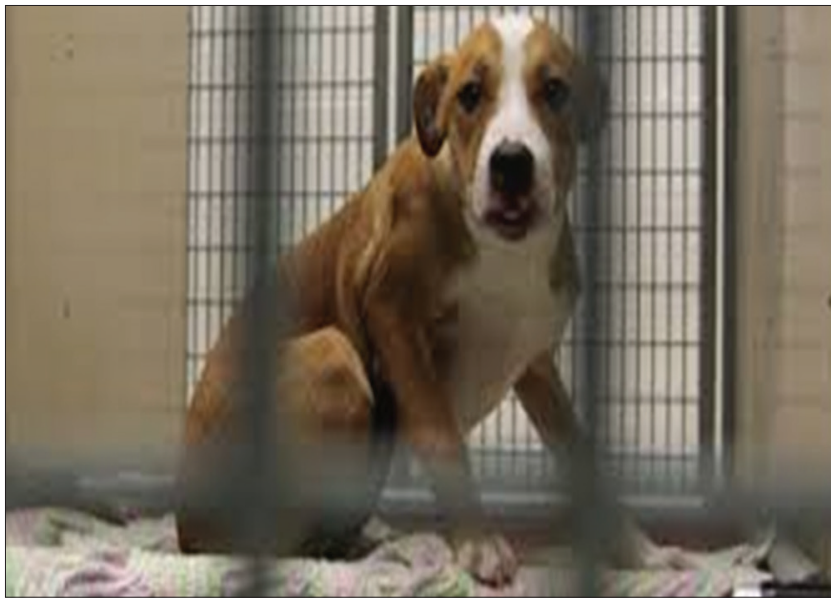

Fig. 1: Dog's stress in artificial shelter

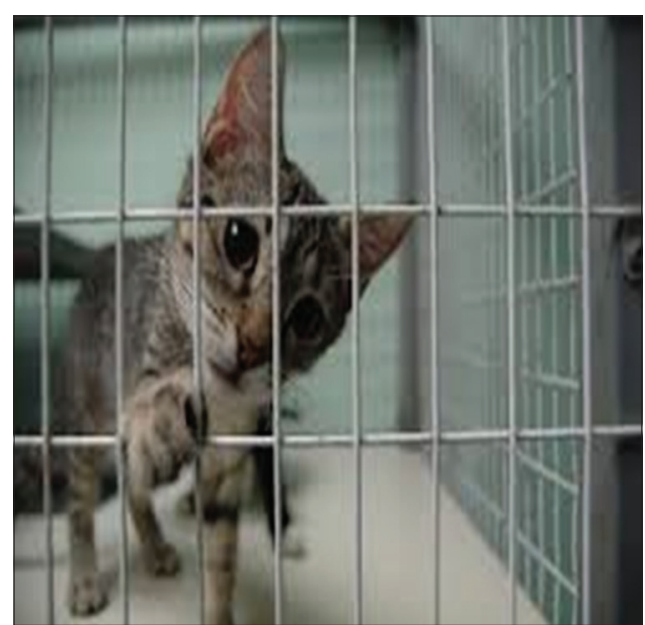

Fig. 2: A stressed cat in an artificial shelter

Table 2: Infants' interaction with pet animals

\begin{tabular}{lll}
\hline Author & Year & Behavioral analysis \\
\hline Wilson et al. & 2003 & $\begin{array}{l}\text { Preventing preschoolchildren } \\
\text { from dog bites }\end{array}$ \\
$\begin{array}{l}\text { Lakestani } \\
\text { Lakestani and }\end{array}$ & 2007 & \\
$\begin{array}{l}\text { Donaldson } \\
\text { Fall et al. }\end{array}$ & 2015 & \\
$\begin{array}{l}\text { Fall } \text { et al. } \\
\text { Pyrhonen } \text { et al. }\end{array}$ & 2015 & $\begin{array}{l}\text { Reducing risk of asthma in } \\
\text { childhood } \\
\text { Cat infections to infants }\end{array}$ \\
\hline
\end{tabular}

Children's interaction with pet cats has been increased. Due to lack of information about pet cats, infants are prone to more infectious diseases such as asthma, allergy, scratch disease, and other grave mental sickness. Cats with furry hairs will cause breathing problem for children [16]. Fig. 4 shows the interaction between a cat and an infant.

\section{Pets' interaction with humans}

Pet animals can identify their owners by their face and voice. Due to lack of knowledge about the pet animals, humans fail to understand the pets' behavioral changes. Table 3 discusses the pets' interaction and recognition of their owners.

In various studies, it has been demonstrated that dogs can differentiate their owners between known and unknown persons and also demonstrated dog's looking behavior when visualizing human faces. In 


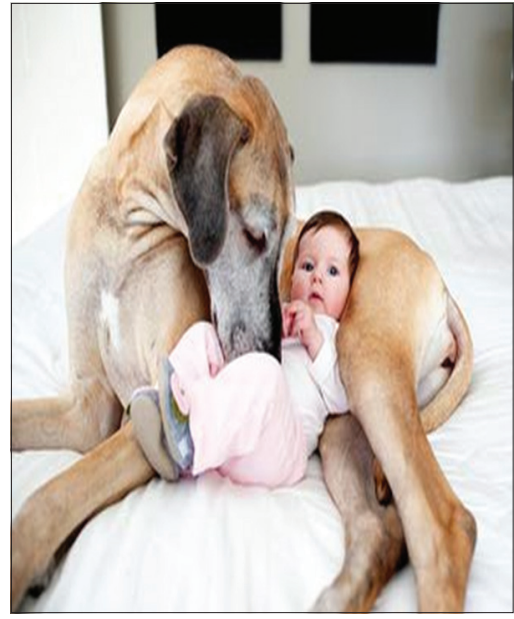

Fig. 3: Dog and infant interaction

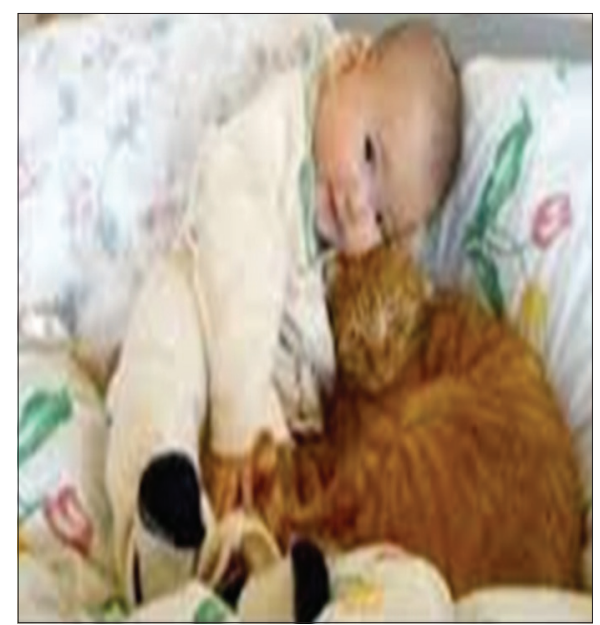

Fig. 4: Cat and infant relation

Table 3: Humans' interaction with pet animals

\begin{tabular}{|c|c|c|}
\hline Author & Year & Behavioral analysis \\
\hline Huber et al. & 2013 & $\begin{array}{l}\text { Human voice identification by } \\
\text { dogs }\end{array}$ \\
\hline Bloom et al. & 2013 & Dog face recognition by owners \\
\hline $\begin{array}{l}\text { Hirskyj-Douglas and } \\
\text { Read }\end{array}$ & 2016 & DCI \\
\hline Hollis & 2001 & $\begin{array}{l}\text { Training and monitoring using } \\
\text { remote unit }\end{array}$ \\
\hline Edwards et al. & 2007 & Attachment evaluation of cat \\
\hline Kelly, et al. & 2011 & Difficulties in shelter \\
\hline Saito and Shinozuka & 2013 & Owner's voice recognized by cat \\
\hline Merola et al. & 2015 & Emotional behavior of cat \\
\hline Yonezawa et al. & 2009 & Cats' high-level behavior \\
\hline Gazzano et al. & 2015 & Learning behavior of kitten cat \\
\hline
\end{tabular}

DCI: Dog-computer interaction

this paper, hetro-specific face perception is used to study the individual experience of the human face [17]. The domestic dog is the perfect model because it has the ability to extract the information from the human face in social-communicative interactions. A dog's ability to discriminate between two familiar faces by the active choice method is examined. Dogs can discriminate people on the basis of visual information and with their active choice.

Humans can read other humans' facial expressions easily. Here, Bloom and Friedman, have examined that humanity has the ability to read dogs' expressions also [18]. Human will identify dog's expression using crossspecies research. Photographs of dogs' facial expressions were taken under various behavioral actions and they are rated by dog experts to test the exact behavior. Dogs' face is recognized by both experienced and inexperienced owners, but experienced people identified the exact behavioral situation of the dogs. It is proven that humans can learn any animals' behavior by closely absorbing their activity daily.

Mancini et al. comprehended that the animal-computer interaction technique helps the owners to gather the requirements and feedback of an animal. Sometimes, the owners may provide wrong information about their pets due to lack of knowledge about them. In dog-computer interaction, Hirskyj-Douglas and Read [19] present the dog information sheet (DISH) for the owners to learn the behavior of their dog's reactions. However, the owners are unable to recognize the dog's behaviors unless they considered themselves as experts. DISH is applied for both animals and human-computer interaction for identifying the reactions.

Hollis [20] used an equipment and method for behavioral monitoring and provided training for an animal; it includes a remote unit with a microprocessor and accelerators. In remote unit, the microprocessor observes and provides instructions from a mass unit and it gets signals from the accelerometers. When the remote unit is placed on an animal, it produces training spur, includes sound or electric shock in response to digging, jumping, barking, leaving a curbed area. Fig. 5 shows a dog and its owner's relationship.

The focus of this study is to identify the affectionate behavior toward cats and their owner. Twenty-eight cats were taken under review with the age range of 1-7 years. To analyze the behavioral characteristics, the cats that are with their owners for a while, newly adopted ones, and the stray cats were considered as samples. Moreover, their interactions and behavioral changes were observed [21].

Previously, the discussion was about the cats' behavior in indoor and outdoor shelter settings. In general, cats have more wisdom to interact with humans and they will easily identify their owner's voice. Saito and Shinozuka studied 20 domestic cats and investigated whether the cats will recognize their owner's voice or not [22]. Cats easily distinguish their owner's voice from stranger's voice. They recorded and played the owner's voice and also three strangers' voice to observe the cats' reactions. The cats' response to human voice is by orienting behavior, not by communicative behavior. An observer identified the cats' orienting behavior, i.e. once they realize their owner's voice, cats act in response by their head and ear movement. Out of 20, 15 cats identified their owner's voice [22].

Communication behavior of the cats toward human is queried using social referencing under the frightening object. Some group of cats observed positive emotional information conveyed by their owners and other group paid negative message from their owners. The main objective is to evaluate whether cats use the same emotional behavior of their owners or use their own behavior while looking at an unfamiliar/frightening object. By categorizing and analyzing the cats' emotional expression, they evaluated the presence of social orienting based on referential glancing toward their owners, vocal and facial reaction from their owner's expressive message, and scrutiny learning from their owners looking at the object. Most of the cats around 79\% displayed referential looking when looking frightened object and only few exhibited expressive messages delivered by their owners [23].

A device is developed to recognize a pet's high-level behavior and post it to twitter of the pet owners. A series of sensing devices such as accelerometer, GPS, and camera were used to form this device, and the pets' behavior is identified using a Bluetooth wireless module [24]. Sensor device is attached to a cat devoid of disturbing its regular activities. Moreover, it will develop the human-pet relationship in a healthy way.

Even though cats have a strong relationship with humans, sometimes, cats show their original behavioral problems. Due to lack of the owner's knowledge in cat's behavior, they misinterpret its activity. After cat 


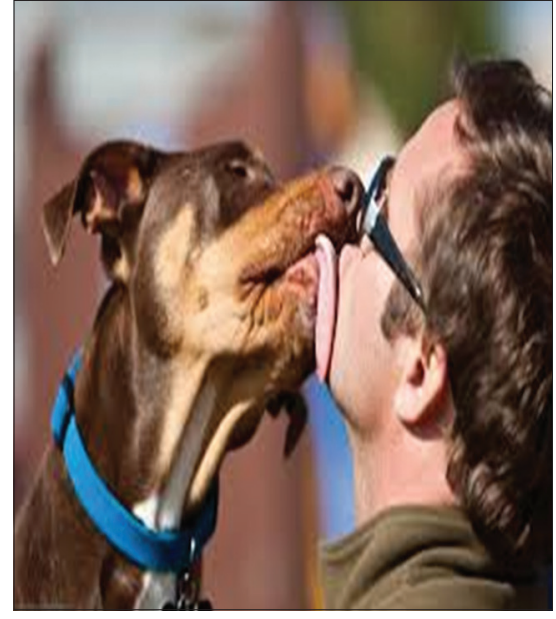

Fig. 5: Dog-owner interaction

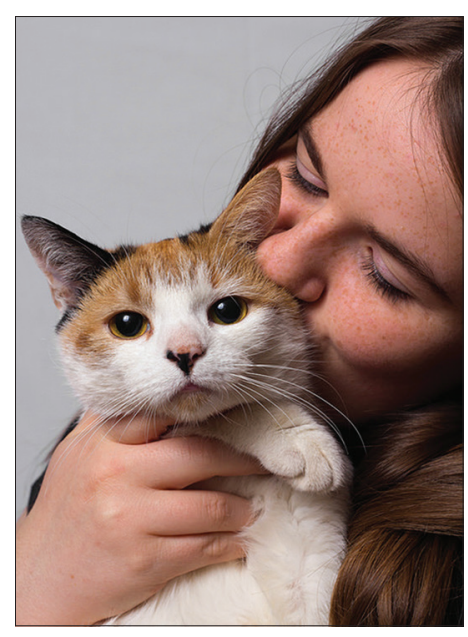

Fig. 6: Cat-owner interaction

adoption, it is difficult to learn kitten cat's activity. In veterinary hospital, during the first visit, they explain the natural behavior of cat, and after 10 months, they interview about the cat's response at home. Few owners find fault about their cat's illegal behavior, but a higher percentage of experimental analysis finds a positive behavior. Individual learning about cat's behavior provides a good relationship with kitten animals [25]. Fig. 6 shows a cat and its owner's relationship.

\section{PETS' AGGRESSIVE BEHAVIOR}

Aggression is the most serious behavioral problem with pet animals. Due to the aggressive behavior, owners should take time to weigh up the situation of their pets' behavioral changes. Table 4 summarizes the violent behavior of pet animals.

Adam Miklosi discussed the behavior of dogs' emotions. The stress level of a dog is measured using questionnaires from the dog owners [26]. Here, dog owners understand the stress by their dogs' displayed behavior. Dog stress can be realized by the owners with a close observation of dogs' habits regularly. It indicates the stress most frequently followed by the result of anxiety and panting (complaining cry or sound). Men can understand dogs' stress level than women. It helps the owners recognize stress level and avoid dog with welfare problems. Results that owners get knowledge of protecting their dog from stress and some owners would gain for their educational efforts.

In general, the social environment shared between dogs and humans is similar. Vocalization is familiar and relevant for both species although
Table 4: Aggressive behavior of pet animals

\begin{tabular}{lll}
\hline Author & Year & Behavioral analysis \\
\hline Miklosi & 2007 & $\begin{array}{l}\text { Dogs' behavior, evolution, and } \\
\text { cognition }\end{array}$ \\
Mariti et al. & 2012 & Stress level \\
Casey et al. & 2014 & Aggressive behavior of dogs \\
Matos et al. & 2015 & \\
Kimberly et al. & 1999 & Gender behavior of cats \\
Rochlitz & 2005 & Cats' behavior in home setting \\
\hline
\end{tabular}

Table 5: Pet animals as a guide for their owners

\begin{tabular}{lll}
\hline Author & Year & Behavioral analysis \\
\hline Sanders & 2015 & Guide dogs help their owners \\
\hline
\end{tabular}

they belong to evolutionarily distant taxonomy. Aggressive behavior of the dogs is analyzed using questionnaires from dog owners. They considered $177 \mathrm{dogs}$ for the study of aggressive behavior Out ofit,nearly $50 \%$ of the dogs showed owner-directed aggression and the remaining showed aggression toward unfamiliar people [27]. Most male dogs and informal training dogs have more aggressive behavior [28]. Gender behavior of the cats is analyzed using statistical operation. Indoor cats, especially neutered domestic cats, are well thought out for behavioral investigation. Totally, 60 households are taken in combination of two male cats, two female cats, or a male and female cat with 10 hrs of daily observation. There was no much difference in aggressiveness based on cats' gender. It takes more time for male/male household observation because the time taken for cats living together is negatively correlated with its aggression rate. The aggression rate will never associate based on the home size and weight of the cats [29].

In the United States, they conduct few studies on the behavior of the cat and how they interact with humans in the home setting environment. The owners have built the home with five freedom provisions that satisfy the cats with protection to express the original behavior and expose their fear and stress levels in that home setting. Most of the U.S. cats are housed in indoor conditions. Here, they discussed the advantages and disadvantages of allowing cats' outdoor access or lock away them in indoors for cat welfare [30].

Pets act as a guide for their owners

Pet animals are trained to assist blind and visually impaired people around the blockades. Guide animal presents a life-shifting experience to the sightless people. Table 5 discusses the service animals for visually unsighted people.

Dogs can help their owners in all kinds of situations. Guide dogs are specially trained to help people with visually harmed; it will easily forecast the situation and environmental changes. To situate the discusses the concepts of individual, communal, and social uniqueness are used. The main significance of working with a guide dog is it forms public relations and how the owner's self-description and social individuality are extended by being thoroughly concerned with the owner-dog team[31]. Fig. 7 shows an assistance dog that helps its blind owner.

Cats are trained to guide their visually impaired owners. Human with sight loss and partial sight will use the guide cat for providing sensible and emotional hold to help people and look the future with self-belief. Fig. 8 shows an service cat that help its unsighted owner.

\section{CONCLUSION}

Animals play a significant role in day-to-day life of a human being in the form of pet animals, investigation animals, security, guide animals, etc. In particular, dogs and cats have more interaction with human beings. Most of the people consider their pet as a part of the family and also 


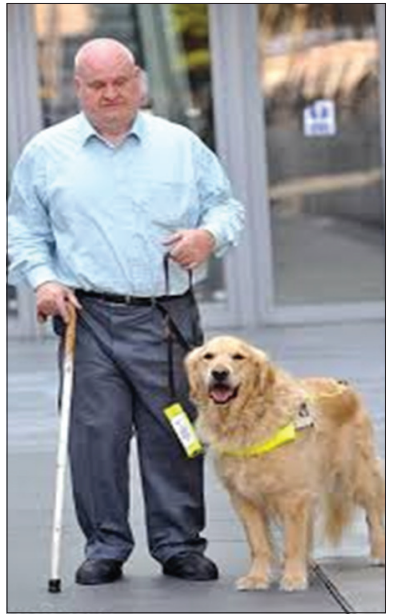

Fig. 7: Guide dog helping its visually blind owner

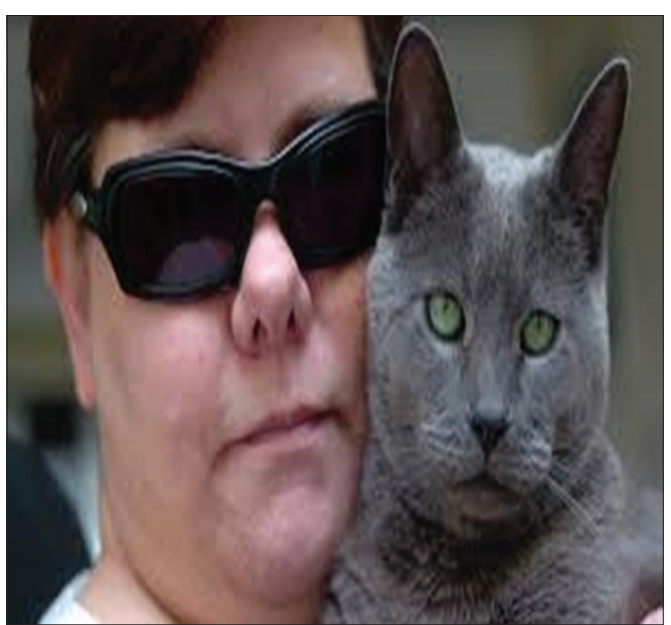

Fig. 8: Guide cat helping its visually blind owner

pets will grant physical and emotional benefits to their owners. In a family, kids are the most affected victims by the pet animals. Pets can enhance the family life even though the proper precautions and training about the animal behavior should be given to the owners as well as family members. Before getting a pet at home, we must consider the health and age of the kids to avoid pet-related infections. Behavioral analysis of a pet is important to safeguard both animals and pet owners. New pet owners should have enough knowledge to identify the pet's behavior, its behavioral changes, aggressive response in the shelter, and vaccination status of the pet before adopting it.

\section{REFERENCES}

1. ASPCA Pet Statistics in U.S. Available from: http://www.aspca.org/ animal-homelessness/shelter-intake-and-surrender/pet-statistics. [Last accessed on 2016 Oct 10].

2. Indian Pet and Equine Industry. Available from: http://www.iiptf. com/indian_pet_industry.php?page=Fact_and_Figure. [Last accessed 2016 Sep 06].

3. AVMA. U.S. Pet Ownership Statistics and Demographics Sourcebook. Available from: https://www.avma.org/KB/Resources/Statistics/Pages/ Market-research-statistics-US-petownership.aspx: American Veterinart Medical Association, Schaumburg, Ill; 2012. [Last cited on 2013].

4. Miklosi A. Dog Behaviour, Evolution and Cognition. Bibliographic Information. Oxford, UK: Oxford University Press; 2007.

5. Serpell JA. Domestication and history of the cat. In: Turner DC, Bateson P, editors. The Domestic Cat: The Biology of its Behavior. $2^{\text {nd }}$ ed. Cambridge: Cambridge University Press; 2000. p. 179-92.
6. Oh J, Fitch WT. CATOS (Computer Aided Training/Observing System): Automating animal observation and training. Behav Res Methods 2016:1-11.

7. Boissy A, Manteuffel G, Jensen MB, Moe RO, Spruijt B, Keeling LJ, et al. Assessment of positive emotions in animals to improve their welfare. Physiol Behav 2007;92(3):375-97.

8. Kathleen NM, Chris T. Tromborg. sources of stress in captivity. Appl Animal Behav Sci 2007:102(3):262-302.

9. Herron ME, Kirby-Madden TM, Lord LK. Effects of environmental enrichment on the behavior of shelter dogs. J Am Vet Med Assoc 2014;244(6):687-92.

10. Kelly G, Magalhães A, de Sousa L. The behaviour of domestic cats in a shelter: Residence time, density and sex ratio. Appl Anim Behav Sci 2011;30(1):53-9.

11. Patronek GJ, Glickman LT, Beck AM, McCabe GP, Ecker C. Risk factors for relinquishment of cats to an animal shelter. J Am Vet Med Assoc 1996;209(3):582-8.

12. Wilson F, Dwyer F, Bennet P. Prevention of dog bites: Evaluation of a brief educational intervention pro-gram for preschool children. J Community Psychol 2003;31(1):75-86.

13. Lakestani NA. Study of Dog Bites and their Prevention. [Ph.D. Thesis]. Edin-burgh: University of Edinburgh; 2007

14. Lakestani N, Donaldson ML. Dog bite prevention: Effect of a short educational intervention for preschool children. PLoS One 2015;10(8): 0134319.

15. Fall T, Lundholm C, Örtqvist AK, Fall K, Fang F, Hedhammar A, et al. Early exposure to dogs and farm animals and the risk of childhood asthma. JAMA Pediatr 2015;169(11):e153219.

16. Pyrhonen K, Nayha S, Larra E. Dog and cat exposure and respective pet allergy in early childhood. Pediatr Allergy Immunol 2015;26(3):247-55.

17. Huber L, Racca A, Scaf B, Virányi Z, Range F. Discrimination of familiar human faces in dogs (Canis familiaris). Learn Motiv 2013;44(4):258-69.

18. Bloom T, Friedman H. Classifying dogs' (Canis familiaris) facial expressions from photographs. Behav Processes 2013;96:1-10.

19. Hirskyj-Douglas I, Read JC. Using Behavioural Information to Help Owners Gather Requirements from their Dogs Responses to Media Technology; 2016.

20. Hollis RL. Dog Behavior Monitoring and Training Apparatus. Headland, Ala: United States Patent; 2001.

21. Edwards C, Heiblum M, Tejeda A, Galindo F. Experimental evaluation of attachment behaviors in owned cats. J Vet Behav Clin Appl Res 2014;2(4):119-25

22. Saito A, Shinozuka K. Vocal recognition of owners by domestic cats (Felis catus). Anim Cogn 2013;16(4):685-90.

23. Merola I, Lazzaroni M, Marshall-Pescini S, Prato-Previde E. Social referencing and cat-human communication. Anim Cogn 2015;18(3):639-48.

24. Yonezawa K, Miyaki T, Rekimoto J. Cat@log: Sensing Device Attachable to Pet Cats for Supporting Human-Pet Interaction. Proceedings of the International Conference on Advance in Computer Entertainment Technology. ACM; p. 149-156.

25. Gazzano A, Bianchi L, Campa S, Mariti C. The prevention of undesirable behaviors in cats: Effectiveness of veterinary behaviorists' advice given to kitten owners. J Vet Behav Clin Appl Res 2015;10(6):535-42.

26. Mariti C, Gazzano A, Moore JL, Baragli P, Chelli L, Sighieri C, et al. Perception of dogs' stress by their owners. J Vet Behav Clin Appl Res 2012;7(4):213-9

27. Matos RE, Jakuba T, Mino I, Fejsakova M, Demeova A, Kottferova J, et al. Characteristics and risk factors of dog aggression in the Slovak Republic. Vet Med 2016;60(8):432-45.

28. Casey RA, Loftus B, Bolster C, Richards GJ, Blackwell EJ. Human directed aggression in domestic dogs (Canis familiaris): Occurrence in different contexts and risk factors. Appl Anim Behav Sci 2014;152:52-63.

29. Kimberly KJ, Crowell-Davis SL. Gender differences in the social behavior of the neutered indoor-only domestic cat. Appl Anim Behav Sci 1999;64(3):193-211.

30. Rochlitz I. A review of the housing requirements of domestic cats (Felis silvestris catus) kept in the home. Appl Anim Behav Sci 2005;93(1):97-109.

31. Sanders CR. The impact of guide dogs on the identity of people with visual impairments. Anthrozoös 2000;13(3):131-9. 